\title{
Comportamento de oviposição e tempo de desenvolvimento de Brachymeria villosa (Oliver) (Hymenoptera, Chalcididae)
}

\author{
Rui Carlos Peruquetti ${ }^{1}$
}

\begin{abstract}
Oviposition behavior and development time of Brachymeria villosa (Oliver) (Hymenoptera, Chalcididae). The oviposition behavior and development time of Brachymeria villosa (Oliver, 1790) on Trypoxylon albitarse Fabricius, 1804 (Sphecidae) is reported. The parasitism occurs through a little hole made by the parasitoid female in the host nest wall. This hole is used by the parasitoid offspring after its emergence to left the host nest. The parasitoid egg is laid on the host larva before it built its cocoon, when such structure is made the parasitoid egg hatch into a larva that feeds on the living host larva and the parasitoid growth enclosed in the host cocoon without build its own. The development time of $B$. villos $a$ was 65 days. From two nest of $T$. albitarse were reared 12 females and one male of $B$. villosa.

KEY WORDS. Chalcididae, Sphecidae, Brachymeria villosa, Trypoxylon, parasitism
\end{abstract}

Brachymeria villosa (Oliver, 1790) é uma espécie neotropical que parasita Trypoxylon albitarse Fabricius, 1804 e T. mexicanum Richards, 1934 (RAU 1940, 1941; BURKS 1960; FriTZ \& Genise 1980; Delvare \& BOUCEK 1992). A despeito dessas informações não se conhece o comportamento de postura e o tempo de desenvolvimento desse parasitóide, os quais são apresentados neste trabalho.

Foi observado (in situ) o comportamento de postura de B. villosa em um ninho de T. albitarse construído na parede de um edifício da Universidade Federal

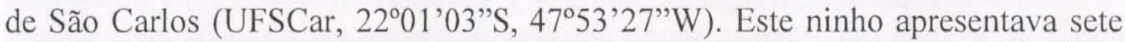
células construídas por uma fêmea, arranjadas em três tubos paralelos, dois deles com três células e o outro com uma.

O parasitismo iniciou-se em 7/IV/1999, vinte dias após a fêmea de $T$. albitarse ter abandonado seu ninho, terminando em 14/IV/1999, quando o ninho foi removido e levado para o laboratório. Foi utilizada a larva parasitada de $T$. albitarse presente na última célula (a única do terceiro tubo) para as observações do início do desenvolvimento de $B$. villosa. A fêmea de $B$. villosa realizou uma postura por dia, por volta das $10 \mathrm{~h}$, com duração de $35,7 \pm 4 \mathrm{D}$.P. minutos $(\mathrm{N}=3)$.

Antes de iniciar o parasitismo do ninho de $T$. albitarse, a fêmea de $B$. villosa voa próximo a ele, inspecionando-o. O padrão de vôo e de colorido da fêmea de B. villosa assemelham-se muito a de alguns Eumeninae (Vespidae) que ocorrem na área de observação. Acredita-se que esta semelhança com alguns Eumeninae e Vespinae (Epiponini) trata-se de uma forma de mimetismo (DELVARE \& BOUCEK 1992).

1) Laboratório de Genética Bioquímica, Departamento de Genética e Evolução, Universidade Federal de São Carlos. 13565-905 São Carlos, São Paulo, Brasil.

E-mail: prcp@iris.ufscar.br 
Após escolher o ninho a ser parasitado, a fêmea de $B$. villosa pousa sobre ele e caminha sobre sua superfície, examinando-o com as antenas. O parasitismo ocorre através da parede do ninho. A fêmea raspa com as mandíbulas, na altura média do eixo longitudinal do ninho, a parede das células que serão parasitas. Quando já existe uma depressão pequena a fêmea passa a usar a extremidade de seu metassoma, friccionando-o e realizando movimentos semicirculares, até perfurar a parede do ninho. Este processo repetiu-se em todas as células parasitadas do ninho. Dessa forma, o ninho fica com várias pontuações características do parasitismo. Após terminar o orifício, o qual no final apresenta formato de cone invertido, apresentando em sua parte superior $2,5 \mathrm{~mm}$ de diâmetro e em sua parte inferior menos de $1 \mathrm{~mm}(\mathrm{~N}=1)$, a fêmea repousa sobre ele e nele introduz o ovipositor, realizando a postura. Foi possível verificar que este orifício, após ser ampliado pelo imago de $B$. villosa, também serve para facilitar a saída da prole do interior do ninho parasitado.

A oviposição de $B$. villosa ocorreu sobre a larva de $T$. albitarse que havia terminado sua alimentação e ainda não iniciado a construção de seu casulo. $\mathrm{O}$ ovo de $B$. villosa só eclodiu depois de seu hospedeiro ter terminado de tecer seu casulo e defecado, o que ocorreu três dias após a oviposição do parasitóide $(\mathrm{N}=1)$. Estes dados confirmam a hipótese de FRITZ \& GENISE (1980) de que $B$. villosa consumiria a larva de $T$. albitarse somente após esta ter defecado. Entretanto, estes autores desconheciam como ocorreria o parasitismo, já que não existem sinais do parasitismo através da parede do casulo do hospedeiro.

A larva do parasitóide não tece casulo no final de seu desenvolvimento, ficando a pupa protegida pelo casulo de seu hospedeiro, que é rompido pelo imago com auxílio de suas mandíbulas, como inferido por RAU (1940).

Foi encontrado um segundo ninho de $T$. albitarse em 22/IV/1999 no campus na UFSCar, com oito células, sendo que sete apresentavam sinais de parasitismo. Seus ocupantes emergiram após $26,4 \pm 5,9$ D.P. dias $(\mathrm{N}=7)$ e o tempo de desenvolvimento total (ovo a imago) de $B$. villosa foi de 65 dias (ninho $1 ; \mathrm{N}=1$ ). Na tabela I são apresentados a duração de cada estádio do desenvolvimento de $B$. villosa.

No primeiro ninho, a razão sexual do parasitóide foi de cinco fêmeas para um macho. Sendo que emergiram três fêmeas e um macho e foram fixadas duas pupas de fêmeas. Do segundo ninho emergiram sete fềmeas de $B$. villosa.

Os adultos examinados foram depositados na coleção do Departamento de Ecologia e Biologia Evolutiva da UFSCar (DCBU) e as pupas e larvas na coleção particular do Dr. M.T. Tavares.

AGRADECIMENTOS. Ȧ Dra. A.M. Penteado-Dias (UFSCar) pela leitura do manuscrito e sugestões. Ao Dr. M.T. Tavares (UNIARA) pela identificação de Brachymeria villosa, incentivo e sugestões. Ao Dr. M.A. Del Lama (UFSCar) pela oportunidade e facilidades oferecidas. Ao Dr. S.T.P. Amarante (MZUSP) pela identificação de Trypoxylon albitarse. À FAPESP pelo auxilio financeiro (Processo no. 98/16390-0) e aos dois revisores anônimos da Revta bras. Zool. pelos comentários e sugestões oferecidas. 
Tabela I. Tempo de desenvolvimento médio ( \pm D.P.) de Brachymeria villosa sobre Trypoxylon albitarse. Entre parênteses o número de observações. (P.O.B) Pupa de olho branco, (P.O.R.) pupa de olho rosa, (P.O.P.) pupa de olho preto.

\begin{tabular}{cc}
\hline Estádio & Tempo em dias \\
\hline Eclosão do ovo & $3,0(1)^{a}$ \\
Larva a P.O.B. & $30,8 \pm 0,7(7)$ \\
P.O.B. a P.O.R. & $10,8 \pm 0,8(6)$ \\
P.O.R. a P.O.P. & $4,6 \pm 0,5(5)$ \\
P.O.P. a Imago & $15,3 \pm 1,3(4)$ \\
Larva a Imago & $61,8 \pm 2,4(4)$ \\
\hline
\end{tabular}

(a) Tempo total de desenvolvimento $=65$ dias.

\section{REFERÊNCIAS BIBLIOGRÁFICAS}

Burks, B.D. 1960. A revision of the genus Brachymeria Westwood in America North of Mexico (Hymenoptera: Chalcididae). Trans. Amer. Ent. Soc. 86: 225-273.

Delvare, G. \& Z. Boucek. 1992. On the new world Chalcididae (Hymenoptera). Mem. Amer. Ent. Inst. 53: 1-466.

FRITZ, M.A. \& J.A. GENISE. 1980. Notas sobre nido de barro de Sphecidae (Hymenoptera). Constructores, inquilinos, parasitoides, cleptoparasitos y detritivoros. Rev. Soc. Entomol. Argent. 39: 67-81.

RaU, P. 1940. Some mud-daubing wasps of Mexico and their parasites. Ann. Ent. Soc. Amer. 33: 590-595.

1941. Observations on certain lepidopterous and hymenopterous parasites of Polistes wasps. Ann. Ent. Soc. Amer. 34: 355-366.

Recebido em 14.XI.2000; aceito em 13.VII.2001. 